|| ISSN(online): 2589-8698 || ISSN(print): 2589-868X ||

International Journal of Medical and Biomedical Studies

Available Online at www.ijmbs.info

NLM (National Library of Medicine ID: 101738825)

Index Copernicus Value 2019: 79.34

Original Research Article

Volume 5, Issue 11; November: 2021; Page No. 62-65

\title{
A STUDY OF KNOWLEDGE AND ATTITUDE ABOUT THE DIABETES, AMONG DIABETIC PATIENTS
}

\section{Dr Vipin Kumar ${ }^{1}$, Dr Maya Pensiya ${ }^{2}$, Dr V B Singh ${ }^{3}$}

${ }^{1}$ Senior resident, General Medicine, Sardar Patel Medical College and P.B.M Hospital, Bikaner

${ }^{2}$ Resident doctor, Ophthalmology, Sardar Patel Medical College and P.B.M Hospital, Bikaner

${ }^{3}$ Senior Professor, General Medicine, Sardar Patel Medical College and P.B.M Hospital, Bikaner

Article Info: Received 09 October 2021; Accepted 13 November 2021

DOI: https://doi.org/10.32553/ijmbs.v5i11.2290

Corresponding author: Dr Maya Pensiya

Conflict of interest: No conflict of interest.

Abstract

Background: The present study was conducted with the aim to determine the knowledge, attitude and practice of diabetes amongst population.

Methods: Hospital based study was conducted on DM patients attending the diabetes center, medicine OPD and medicine IPD within the study period were recruited in the study after taking written inform consent.

Results: Regarding knowledge about complications of diabetes i.e. heart disease stated to be the highest in patients which was $201(40.2 \%)$ followed by wound healing $110(22.00 \%)$, eye disease 102(20.4\%), peripheral neuropathy $96(19.2 \%)$ and kidney diseases $92(18.4 \%)$.

Conclusion: From our study it was concluded that Knowledge about what disease is, was good and regarding symptoms (frequent urination) was also good but complication(Heart disease, stroke, kidney disease, eye disease, peripheral neuropathy, wound healing) was poor.

Keywords: DM, OPD, IPD.

\section{Introduction:}

Diabetes Mellitus (DM) is one of the most challenging public health problems in $21^{\text {st }}$ century. ${ }^{1}$ It is important to know about the awareness level of a disease condition in a population, which plays a vital role in future development, early detection and prevention of disease. Prevention is important because the burden of the diabetes and its complications on health care and its economic implications are enormous, especially for a developing country like India. Patient education is always considered an essential element of DM management ${ }^{2}$.

The increase in diabetes amongst low-resource countries is partly due to lack of knowledge and awareness about the disease as it is insidious in onset and people remain undiagnosed until major complications set in. Knowledge plays a pivotal role in any development of disease and its early detection and prevention. Patients with diabetes should have positive knowledge, attitude and practice. All these elements are closely related to each other and are dependent on each other. As diabetes is concerned, the knowledge, attitude and practice are dependent on socioeconomic background, habits and cultural beliefs. Proper knowledge of diabetes mellitus can prevent the occurrence of chronic complications associated with DM, which significantly influence the quality of life of patients with diabetes. ${ }^{3}$
Most studies have used measurements such as blood glucose level and knowledge, attitude and practice (KAP) as the index of diabetes management. Very few studies have been conducted in North Western Rajasthan to evaluate the level of awareness, attitudes and practices among patients with DM so the present study was conducted with the aim to determine the knowledge, attitude and practice of diabetes amongst population.

\section{Material and Methods}

Study design: Hospital based cross-sectional study.

Study place: Dept. of General Medicine, S.P.Medical College and P.B.M Hospital, Bikaner

Study population: DM patients attending the diabetes center, medicine OPD and medicine IPD within the study period were recruited in the study after taking written inform consent.

\section{Inclusion Criteria:}

$>$ Dm patients attending the diabetes center, medicine OPD \& IPD

$>$ Willing to participate in the study.

Exclusion Criteria:

$>$ Patients less than 14 years 
Patients are not willing to participate in the study.

\section{Data Collection:}

Once included, a structured and validated questionnaire form was filled up by the study subjects after being properly explained by the principal investigator and enough time was provided to each patient. Socio-demographic information (age, sex, occupation, residence, education), family history of diabetes, history of alcohol and history of tobacco consumption was recorded. The questionnaire also contained a series of questions on awareness of DM knowledge.
Data Analysis:

All data were analyze on EPI-info statistical software.

Qualitative data were expressed in the form of proportion.

Quantitative data were expressed in mean \pm SD

Qualitative data were compared by Chi square test Unpaired t test were use to infer the difference in means.

Results

Table 1: Socio-demographic variable

\begin{tabular}{|l|l|l|l|l|l|l|}
\hline \multirow{3}{*}{ Age group (yrs) } & \multicolumn{2}{l|}{ Sex } & \multicolumn{2}{l|}{ Total } \\
\cline { 2 - 6 } & \multicolumn{2}{|l|}{ Female } & Male & \multirow{2}{*}{ Percentage } \\
\cline { 2 - 6 } & No & Percentage & No & Percentage & & \\
\hline $19-30$ & 2 & 33.33 & 4 & 66.67 & 6 & 1.2 \\
\hline $31-45$ & 21 & 35.00 & 39 & 65.00 & 60 & 12.00 \\
\hline $46-60$ & 87 & 43.50 & 113 & 56.50 & 200 & 40.00 \\
\hline $61-75$ & 83 & 41.09 & 119 & 58.91 & 202 & 40.4 \\
\hline$>75$ & 19 & 59.37 & 13 & 40.63 & 32 & 6.4 \\
\hline Total & 212 & 42.40 & 288 & 57.60 & 500 & 100.00 \\
\hline
\end{tabular}

P-value $=0.244$

In our study out of 288 male subject, 87 subject were from 46-60 yrs age group followed by 83 subject were from 61-75 yrs age group and out of 212 female subject maximum 119 subject were from 61-75 yrs age group.

Table 2: Respondent's correct knowledge regarding diabetes mellitus $(\mathbf{n}=500)$.

\begin{tabular}{|l|l|l|}
\hline Variable & No of subject & Percentage \\
\hline What is diabetes? & 409 & 81.80 \\
\hline What causes diabetes? & 364 & 72.80 \\
\hline Know about type of diabetes? & 360 & 72.00 \\
\hline Is diabetes related to life style? & 478 & 95.60 \\
\hline Diabetes is diagnosed by blood sugar examination? & 360 & 72.00 \\
\hline Is obesity related to diabetes? & 477 & 95.40 \\
\hline Can smoking / alcohol is lead to diabetes ? & 454 & 90.80 \\
\hline Can excessive sugar intake lead to diabetes ? & 431 & 86.20 \\
\hline Is diabetes Hereditary? & 46 & 9.20 \\
\hline Diabetes canot be cured? & 477 & 95.40 \\
\hline Can complication develop in diabetic subject due to diabetes? & 387 & 77.40 \\
\hline
\end{tabular}

On the knowledge regarding diabetes questionnaire, the assessment regarding the knowledge of diabetes was good as 409 $(81.80 \%)$ of the population knows what diabetes is and $364(72.80 \%)$ knows the causes of diabetes. It was observed that 46 $(9.20 \%)$ had knowledge about the hereditary nature of the disease, $360(72.0 \%)$ had correctly answered that diabetes can be diagnosed by blood sugar examination. $454(90.80 \%)$ said that quitting smoking or alcohol is beneficial for control. 477 $(95.40 \%)$ knows that diabetes canot be cured. 
Table 3: Respondents correct knowledge about symptoms of diabetes $(n=500)$.

\begin{tabular}{|l|l|l|}
\hline Symptoms & No of subject & Percentage \\
\hline Frequent urination & 454 & 90.8 \\
\hline Frequent hunger & 32 & 6.4 \\
\hline Frequent thirst & 31 & 6.2 \\
\hline Weight loss & 30 & 6.00 \\
\hline Numbness & 60 & 12.00 \\
\hline Don't know & 40 & 8.00 \\
\hline
\end{tabular}

It was observed that $454(90.8 \%)$ knew that frequent urination is the most common symptom of diabetes whereas symptoms such as frequent huger(6.4\%), frequent thirst $(6.2 \%)$, weight loss $(6.00 \%)$ and numbness in feet $(12.00 \%)$ was low.

Table 4: Respondents correct knowledge about risk factors of diabetes $(n=500)$.

\begin{tabular}{|l|l|l|}
\hline Risk factor & No of subject & Percentage \\
\hline Obesity & 319 & 63.8 \\
\hline Increasing age & 412 & 82.4 \\
\hline Family history & 423 & 84.6 \\
\hline Sedentary life style & 350 & 70.00 \\
\hline Mental stress & 380 & 76.00 \\
\hline Hypertension & 160 & 32.00 \\
\hline Fast food & 350 & 70.00 \\
\hline High cholesterol & 84 & 16.8 \\
\hline Don't know & 40 & 8.00 \\
\hline
\end{tabular}

It was observed that mental stress, sedentary life style, overweight, increasing age and oily food i.e. $76.00 \%, 70.00 \%$, $63.8 \%, 82.4 \%$ and $70.00 \%$ respectively were common risk factor of diabetes known to subject. $8.0 \%$ subject were found to have no knowledge regarding the risk factors.

Table 5: Respondents correct knowledge about complications of diabetes $(n=500)$.

\begin{tabular}{|l|l|l|}
\hline Complication & No of subject & Percentage \\
\hline Heart disease & 201 & 40.2 \\
\hline Eye disease & 102 & 20.4 \\
\hline Peripheral neuropathy & 96 & 19.2 \\
\hline Stroke & 94 & 18.8 \\
\hline Kidney problem & 92 & 18.4 \\
\hline Wound healing & 110 & 22.0 \\
\hline
\end{tabular}

Regarding knowledge about complications of diabetes, heart disease was stated to be the highest in subject which was $201(40.2 \%)$ followed by wound healing $110(22.00 \%)$, eye disease 102(20.4\%), peripheral neuropathy $96(19.2 \%)$ and kidney diseases $92(18.4 \%)$.

\section{Discussion}

The increasing prevalence of diabetes and its complications in India would pose a real threat to existing health services. Awareness about risk factors of diabetes and its treatment can assist in early prevention of its complication and reduce incidence of diabetes.

On the knowledge regarding diabetes questionnaire, the assessment regarding the knowledge of diabetes was good as $409(81.80 \%)$ participants knew what diabetes is and 364 $(72.80 \%)$ knew the causes of diabetes. It was observed that $46(9.20 \%)$ had knowledge about the hereditary nature of the disease, $360(72.0 \%)$ had correctly answered that diabetes can be diagnosed by blood sugar examination. 454 $(90.80 \%)$ said that quitting smoking or alcohol is beneficial for control. $477(95.40 \%)$ knew that diabetes canot be cured.

In a study done by Khandelwal $\mathrm{A}$ et $\mathrm{al}^{4}$ observed that the assessment regarding the knowledge of diabetes was good as $187(62.3 \%)$ of the population knows what diabetes is and $163(54.3 \%)$ knows the causes of diabetes. It was observed that $201(69.0 \%)$ had knowledge about the hereditary nature of the disease, $274(91.3 \%)$ correctly answered regarding non-infectious nature of the disease and $279(93.0 \%)$ had correctly answered that diabetes can be diagnosed by blood sugar examination. 235 (78.3\%) were aware of importance of exercise for the control of disease while $226(75.3 \%)$ said that modification in diet is essential for the control of the disease. $221(73.7 \%)$ said 
that quitting smoking or alcohol is beneficial for control. Drugs should be continued even after control of blood sugar was the response from the $240(80.5 \%)$ and 215 $(71.6 \%)$ knows that diabetes can be cured. Their result were similar to our study.

In a study done by Nagar $\mathrm{V}$ et al. ${ }^{5}$ observed that around $16 \%$ of the participants scored 15 or more out of total score of 26, and were categorised as having good level of knowledge, $34.6 \%$ of participants scored less than or 9 (poor knowledge) and $49.3 \%$ scored between 10 to 14 points (moderate knowledge). 67\% patients were aware that diabetes is characterised by raised blood sugar. Only $26 \%$ patients knew that diabetes is characterized by higher blood glucose level than normal whereas most of them $(32 \%)$ think that increased urination is the only symptom of diabetes. Out of 250 patients only $29 \%(n=88)$ knew the normal range of blood glucose level. About two-third $(62 \%)$ of the participants knew that diabetes can cause complication or organ damage in which most of the patient's stated eye and kidney as the commonest site for complication. $14 \%$ of the population didn't know any kind of complications regarding the diabetes. $41 \%$ people were aware that diabetes can prevented by healthy diet and regular exercise and about $24 \%$ of them think that blood pressure control is necessary in diabetes whereas only $29 \%$ patients were aware about the symptom of hypoglycaemia. Their result were similar to our study.

It was observed that mental stress, sedentary life style, overweight, increasing age and oily food i.e. $76.00 \%$, $70.00 \%, 63.8 \%, 82.4 \%$ and $70.00 \%$ respectively were common risk factor of diabetes known to patients. $8.0 \%$ patients were found to have no knowledge regarding the risk factors.

The finding suggests need for adequate counseling of all diabetic patients not only at the time of diagnosis but time and again at each and every follow up visit in order to reinforce the importance of drug compliance. The findings of the present study were quite similar to the findings of studies conducted on knowledge on risk factors of diabetes in different population groups. ${ }^{6}$ In contrast to our findings, a study conducted in Warangal revealed that $63.5 \%$ of the participants correctly knew that there was no relation between excess sweet consumption and causation of diabetes. $^{7-8}$

The findings are consistent to the study conducted in Saudi Arabia, where obesity and lack of physical exercise were the risk factors of diabetes as most frequently stated by the respondents. ${ }^{7}$ However, in a Chennai study, it was found that knowledge about the role of obesity and physical inactivity in the occurrence of diabetes was very low, with only $12 \%$ of study subjects reported these as the risk factors for diabetes. ${ }^{9}$

\section{Conclusion}

From our study it was concluded that Knowledge about what disease is, was good and regarding symptoms (frequent urination) was also good but complication(Heart disease, stroke, kidney disease, eye disease, peripheral neuropathy, wound healing) was poor.

\section{References}

1. World Health Organization, Global Report on Diabetes. Geneva, 2016. (Last Accessed 30 Dec. 2018. )

2. "Diabetes can be controlled in 80 percent of Cases in India". IANS. news. biharprabha.com. Retrieved 6 February 2014.

3. Demaio AR, Otgontuya D, de Courten M, Bygbjerg IC, Enkhtuya P, et al. Exploring knowledge, attitudes and practices related to diabetes in Mongolia: a national population-based survey. BMC Public Health 2013;13: 236.

4. Khandelwal A, Mathur HN, Jain J, Dixit M, Singhal G, Khandelwal N. A study of knowledge about the diabetes type I and II, among diabetic patients in Geetanjali medical college and hospital, Udaipur, Rajasthan, India. Int $\mathbf{J}$ Community Med Public Health 2016;3:1278- 81.

5. Nagar V, Prasad P, Mitra A, Kale S, Yadav K, Shukla M. Assessment of knowledge, attitude and practice about diabetes among diabetic patients of tertiary care centre in central India. Int $\mathrm{J}$ Community Med Public Health 2018;5:4065-71.

6. Wee HL, Ho HK, Li SC. Public awareness of diabetes mellitus in Singapore. Singapore Med J. 2002;43(3):128-34.

7. Padma K, Bele SD, Bodhare TN, Valsangkar S. Evaluation of knowledge and self-care practices in diabetic patients and their role in disease management. Nat J Com Med. 2012;3(1):3-6.

8. Shankar PS, Ramya N. Non-adherence to diabetic treatment and its effect on glycaemic control, study at a rural hospital of Tiruchirappalli, Tamilnadu, India. The Internet J Health. 2011;2:13.

9. Aljoudi AS, Taha AZA. Knowledge of diabetes risk factors and preventive measures among attendees of a primary care center in eastern Saudi Arabia. Ann Saudi Med. 2009;29(1):15-9. 